\title{
Analisis Sistem Penjaminan Mutu Internal (SPMI) SMA Negeri di Kota Mataram
}

\author{
Gunawan $^{1}$, Agus Ramdani', Fahruddin Fahruddin ${ }^{3}$ \\ 1,2,3 Magister Administrasi Pendidikan \\ Email: gunn.aawan11@gmail.com
}

\begin{abstract}
Education quality standards are important things that must be possessed by educational institutions including at the level of the education unit. The quality assurance that has been running so far is still limited to external quality assurance, while the internal quality assurance of the Education unit has not been widely implemented by every Education unit. This study aims to determine how the implementation and evaluation of the education quality assurance system in SMAN 6 Mataram City. The method used is descriptive qualitative. Data collection was carried out through interviews, observation and documentation. Data analysis shows that SMA Negeri 6 Mataram is in implementing quality compliance, from the results of interviews with researchers with the principal, deputy principal and head of the TPMPS Team, it is found that all school components are actively involved in school activities, both in analyzing activities and program design and having commitment which is high for the fulfillment of the quality compliance component, this can be seen from the involvement in participating in the activities and programs that have been planned by the school. Based on these findings, it is suggested that 1) SMAN Kota Mataram need to implement quality assurance under certain operational units, 2) empower school administrators by implementing school-based management, 3) there is a need for teachers and administrative staff to be educated about the importance of quality culture.
\end{abstract}

Keywords: Analysis, SPMI, SMA 6 Mataram, Implementation

Abstrak: Standar mutu Pendidikan menjadi hal penting yang harus dimiliki oleh Lembaga Pendidikan termasuk dalam level satuan Pendidikan. Penjaminan mutu yang selama ini sudah berjalan masih terbatas penjaminan mutu eksternal, sedangkan penjaminan mutu internal satuan Pendidikan belum banyak dilaksanakan oleh setiap satuan Pendidikan. Penelitian ini bertujuan untuk mengetahui bagaimana penerapan dan evaluasi sistem penjaminan mutu pendidikan di SMAN 6 Kota Mataram. Metode yang digunakan adalah deskriptif kualitatif. Pengumpulan data dilakukan melalui wawancara, observasi, dan dokumentasi. Analisis data menunjukkan bahwa SMA Negeri 6 Mataram dalam melaksanakan pemenuhan mutu, dari hasil wawancara peneliti dengan kepala sekolah, wakil kepala sekolah dan ketua Tim TPMPS diperoleh keterangan bahwa semua komponen sekolah terlibat aktif dalam kegiatan sekolah, baik dalam menganalisis kegiatan dan racangan program serta memiliki omitmen yang tinggi untuk pemenuhan komponen pemenuhan mutu, hal ini dapat dilihat dari keterlibatan dalam mengikuti kegiatan dan program yang telah diencanakan oleh sekolah. Berdasarkan temuan ini, disarankan agar 1) SMAN Kota Mataram perlu menerapkan penjaminan mutu di bawah unit operasional tertentu, 2) perlu adanya pemberdayaan pengelola sekolah dengan menerapkan manajemen berbasis sekolah, 3) adanya kebutuhan bagi guru dan staf administrasi untuk dididik tentang pentingnya budaya mutu.

Kata Kunci: Analisis, SPMI, SMA 6 Mataram, Pelaksanaan

\section{PENDAHULUAN}

Guru merupakan sumber daya manusia yang berperan signifikan sebagai penggerak dalam suatu sekolah (Murtiningsih, et al., 2019). Tercapai atau tidaknya visi, misi dan tujuan sekolah tergantung kepada personil yang ada di sekolah tersebut, baik secara individu maupun secara tim (Muhammad, 2016). Untuk mencapai tujuan sekolah dapat dilihat dari kinerja guru, karena guru memegang peran penting dalam kegiatan belajar mengajar, dimana guru harus berinteraksi langsung dengan para peserta didik (Hasanah \& Kristiawan, 2019). Karena guru mempunyai peranan penting dalam dunia pendidikan, maka guru harus memiliki kinerja yang baik (Resawati \& Larashati, 2017).
Penjaminan mutu pendidikan di Indonesia tidak lepas dari peran pemerintah yang menetapkan Standar Nasional Pendidikan (SNP) sebagai tolak ukur mutu pendidikan baik di tingkat dasar dan menengah (Taurina, 2015). Penjaminan Mutu Pendidikan mengacu pada SNP yang diatur dalam UU Sistem Pendidikan Nasional meliputi delapan standar nasional pendidikan. Kedelapan standar itu ialah standar isi, standar proses, standar kompetensi lulusan, standar pendidik dan tenaga kependidikan, standar sarana dan prasarana, standar pengelolaan, standar pembiayaan, dan standar penilaian pendidikan (Badan Nasional Akreditasi, 2019).

Berdasarkan observasi awal pada Sekolah Menengah Atas (SMA) Negeri yang berada di kota Mataram seluruhnya 
melaksanakan proses evaluasi pelaksanaan pemenuhan mutu oleh pemerintah melalui penyelenggara di satuan pendidikan. dari Seluruh siklus ini dilaksanakan oleh satuan pendidikan dalam pemenuhan Pemetaan mutu satuan pendidikan berdasarkan Standar Nasional Pendidikan, Perencananaan peningkatan mutu yang dituangkan dalam rencana strategis, fasilitasi pemenuhan mutu di seluruh satuan pendidikan, monitoring dan evaluasi terhadap proses pelaksanaan pemenuhan mutu, Penetapan dan evaluasi Standar Nasional Pendidikan, Pelaksanaan akreditasi satuan pendidikan. Berdasarkan data Hasil Akreditasi untuk Jenjang SMA Negeri di Kota Mataram yang mencakup semua komponen delapan Standar Nasional Pendidikan dan diperoleh data Akreditasi seperti pada tabel di bawah ini.

Kenyataanya, tidak semua satuan pendidikan memperhatikan pengelolaan penjaminan mutu baik (Tavares, et al., 2017; Mursidi, etb al., 2020). Tidak semua lembaga pendidikan dan yayasan pendidikan memiliki manajemen pengelolaan penjaminan mutu yang terstruktur, sistematis, dan berkelanjutan (Sumarto, 2018). Hal ini terjadi karena banyaknya jumlah satuan pendidikan dengan visi misi yang beragam. Kendali mutu menjadi tolak ukur eksistensi satuan pendidikan di tengah-tengah pilihan masyarakat (Aspranawa \& Pravitasari, 2017).

Persaingan mutu antar satuan pendidikan membuat masyarakat semakin paham dan kritis dalam memilih sekolah yang tepat bagi putra-putri mereka (Mursidi, et al., 2019). Penilaian Akreditasi yang dilakukan oleh Badan Akreditasi Nasional (BAN) membuat masyarakat memahami pentingnya nilai akreditasi dalam memilih sekolah. Oleh karena itu menjadi penting bagi setiap satuan pendidikan untuk mempertahankan kualitas mutu pendidikan dengan tetap memenuhi kedelapan standar pendidikan nasional. Penelitian ini bertujuan untuk mengetahui pelaksanaan dan evaluasi sistem penjaminan mutu internal SMA Negeri di Kota Mataram

\section{METODE PENELITIAN}

Penelitian ini menggunakan metode deskriptif dengan pendekatan kualitatif (Arikunto, 2019). Penelitian ini bukan bertujuan bertujuan untuk mengetahui pelaksanaan dan evaluasi Sistem Penjaminan Mutu Internal (SPMI) SMA Negeri di Kota Mataram, dengan meliputi: perencanaan dan pelaksanaan SPMI. Penelitian kualitatif disebut juga penelitian dengan pendekatan naturalistik, karena situasi lapangan penelitian bersifat natural, wajar, apa adanya, tanpa di manipulasi dan diatur dengan eksperimen atau test (Anggito \& Setiawan, 2018).

Data yang akan diperoleh dalam penelitian ini adalah: data primer dan sekunder. Data primer didapat dari wawancara dan observasi, sedangkan data sekunder diperoleh melalui dokumen, catatan dan sumber lainya yang berkenaan dengan fokus penelitian yaitu SMA Negeri di Kota Mataram.

Teknik pengumpulan data menggunakan lembar observasi, wawancara, dokumentasi dan angket. Teknik analisis data menggunakan tiga alur kegiatan yaitu reduksi data, penyajian data dan penarikan kesimpulan. Sedangkan dalam mengecek keabsahan data penelitian ini dilaksanakan dengan kredibilitas, transferbilitas dan dependibilitas.

\section{HASIL DAN PEMBAHASAN}

Pemenuhan mutu pada komponen pelaksanaan merupakan program dan kegiatan pemenuhan delapan Standar Nasional Pendidikan yang telah disusun dalam rencana kerja sekolah (RKLM/RKT). Hal ini sesuai yang disampaikan oleh kepala SMA Negeri 6 Mataram sebagai informan pertama sebagai berikut:

Dalam pelaksanaan pemenuhan mutu SMA Negeri 6 Mataram

"Pelaksanaan pemenuhan mutu di SMA Negeri 6 berpedoman pada rencana pemenuhan mutu yang telah disusun oleh kepala sekolah, kepala sekolah, komite sekolah yang tertuang pada LK 3 Tim 
penjaminan mutu Pendidikan sekolah SMA Negeri 6 Mataram" (F3.W.Pm6.AT.17.11.2020)

Sedangkan informasi kedua menurut ketua Tim Penjaminan mutu pendidikan sekolah (TPMPS) SMA Negeri 6 Mataram:

"Pelaksanaan pemunahan mutu di SMA Negeri 6 Mataram tetap mengacu kepada rencana pemenuhan mutu yang menjadi kesepakatan dan acuan sekolah yang telah dirumuskan berdasarkan komitmen dari sekolah melalui guru dan smua komponen sekolah berdasarkan kemampuan sumber daya manusi dan kemampuan keuangan sekolah yang di rancang di RKAS “(F3.W.Pm6.ES 17.11.2020)

Pelaksanaan pemenuhan mutu di SMA Negeri 6 Mataram pada dasarnya diperoleh dari Kepala sekolah, Wakil kepala Sekolah, Guru, Pegawai dan Tim Penjamian Mutu Pendidikan Sekolah (TPMPS) yang diputuskan untuk melaksanakan kegiatan yang berdasarkan rencana pemenuhan mutu untuk masing- masing standar anatara lain:

\section{a. Standar Kompetensi Lulusan}

\section{SMA Negeri 6 Mataram}

Dengan mengacu kepada rencana pemenuhan mutu pada standar kompetensi lulusan yang perlu di pertahankan dan ditingkatkan. Hasil pelaksanaan pemenuhan mutu pada standar kompetensi lulusan disajikan pada Tabel 1.

Tabel 1. Pelaksanaan Pemenuhan Mutu Pada Standar Kompetensi Lulusan

\begin{tabular}{|l|l|c|l|l|}
\hline \multicolumn{1}{|c|}{ Kegiatan } & $\begin{array}{c}\text { Waktu } \\
\text { pelaksanaan }\end{array}$ & $\begin{array}{c}\text { Penanggung } \\
\text { Jawab }\end{array}$ & Peserta & Sumber Daya \\
\hline $\begin{array}{l}\text { Melaksanakan kegiatan } \\
\text { workshop penilaian sikap }\end{array}$ & Agustus 2019 & $\begin{array}{c}\text { Wakasek } \\
\text { kurikulum }\end{array}$ & Guru & $\begin{array}{l}\text { Dana BOS, BPP } \\
\text { (sarpras dan SDM) }\end{array}$ \\
\hline $\begin{array}{l}\text { Melaksanakan kegiatan } \\
\text { Workshop tentang model } \\
\text { pembelajaran }\end{array}$ & $\begin{array}{l}\text { Agustus- } \\
\text { september } \\
2019\end{array}$ & $\begin{array}{c}\text { Wakasek } \\
\text { kurikulkum }\end{array}$ & Guru & $\begin{array}{l}\text { Dana BOS, BPP } \\
\text { (sarpras dan SDM) }\end{array}$ \\
\hline $\begin{array}{l}\text { Melaksanakan kegiatan } \\
\text { workshop tentang metode } \\
\text { pembelajaran aktif dan } \\
\text { inovatif }\end{array}$ & $\begin{array}{l}\text { Agustus- } \\
\text { september }\end{array}$ & $\begin{array}{c}\text { Wakasek } \\
\text { kurikulum }\end{array}$ & Guru & $\begin{array}{l}\text { Dana BOS, BPP } \\
\text { (sarpras dan SDM) }\end{array}$ \\
\hline
\end{tabular}

(Sumber: LK3 TPMPS SMA Negeri 6

\section{b. Standar Isi}

Mataram tahun 2019)

\section{SMA Negeri 6 Mataram}

Berdasarkan analisis mutu pada standar isi diperoleh kekuatan pada tiap ketiga indikator. direkomendasikan untuk mempertahankan meningkatkan pemenuhan tiap indikator.
Dalam hal ini pemenuhan pada pelaksanaan program pemenuhan mutu pada standar isi yaitu penyempurnaan perangkat kurikulum dan penguatan pelajaran muatan lokal bahasa daerah. Hasil pelaksanaan pemenuhan mutu pada standar isi disajikan pada Tabel 2.

Tabel 2. Pelaksanaan Pemenuhan Mutu Pada standar Isi

\begin{tabular}{|c|c|c|c|c|}
\hline Kegiatan & $\begin{array}{c}\text { Waktu } \\
\text { pelaksanaan }\end{array}$ & Penanggung Jawab & Peserta & Sumber Daya \\
\hline $\begin{array}{l}\text { 1. Workshop Pelatihan } \\
\text { penyempurnaan RPP } \\
\text { 2. Workshop } \\
\text { penyusunan atau } \\
\text { revisi dokumen } \\
\text { Kurikulum }\end{array}$ & Juli 2019 & Wakasek kurikulum & Guru & $\begin{array}{l}\text { Kepala } \\
\text { Sekolah, } \\
\text { komite sekolah } \\
\text { Guru dan } \\
\text { Narasumber }\end{array}$ \\
\hline $\begin{array}{l}\text { 1. IHT/Workshop } \\
\text { tentang } \\
\text { pengembangan } \\
\text { KTSP dan } \\
\text { pendalaman materi } \\
\text { mata pelajaran } \\
\text { mulok }\end{array}$ & Juli 2019 & Wakasek kurikulkum & Guru & $\begin{array}{l}\text { Kepala } \\
\text { Sekolah, } \\
\text { komite sekolah } \\
\text { Guru dan } \\
\text { Narasumber }\end{array}$ \\
\hline
\end{tabular}

(Sumber: LK3 TPMPS SMA Negeri 6

Mataram Tahun 2019)

\section{c. Standar Proses}

\section{SMA Negeri 6 Mataram}

Berdasarkan analisis mutu pada standar proses diperoleh kekuatan pada tiap indikator ketiga indikator. direkomendasikan untuk mempertahankan meningkatkan pemenuhan tiap indikator. Dalam hal ini pemenuhan pada pelaksanaan program pemenuhan mutu pada standar proses yaitu proses penilaian pembelajaran HOTS beserta kisi-kisi. Hasil pelaksanaan pemenuhan mutu pada standar proses disajikan pada Tabel 3.

Tabel 3. Pelaksanaan Pemenuhan mutu pada standar Proses

\begin{tabular}{|c|l|c|c|c|}
\hline \multicolumn{1}{|c|}{ Kegiatan } & $\begin{array}{c}\text { Waktu } \\
\text { pelaksanaan }\end{array}$ & $\begin{array}{c}\text { Penanggung } \\
\text { Jawab }\end{array}$ & Peserta & Sumber Daya \\
\hline $\begin{array}{l}\text { IHT proses } \\
\text { penilaian HOTS } \\
\text { beserta kisi-kisi }\end{array}$ & $\begin{array}{l}\text { September- } \\
\text { Oktober 2019 }\end{array}$ & $\begin{array}{c}\text { Wakasek } \\
\text { kurikulum }\end{array}$ & Guru & $\begin{array}{l}\text { - Narasumb } \\
\text { er yang } \\
\text { kompeten } \\
\text { - Guru }\end{array}$ \\
\hline
\end{tabular}

(Sumber: LK3 TPMPS SMA Negeri 6 Mataram Tahun 2019)

\section{d. Standar Penilaian \\ SMA Negeri 6 Mataram}

Berdasarkan analisis mutu pada standar Penilaian diperoleh kekuatan pada kelima indikator. direkomendasikan untuk mempertahankan pemenuhan tiap indikator. 
Dalam hal ini pemenuhan pada pelaksanaan program pemenuhan mutu pada standar Penilaian disajikan pada Tabel 4.

Tabel 4. Pelaksanaan Pemenuhan Mutu Pada standar Penilaian Pendidikan

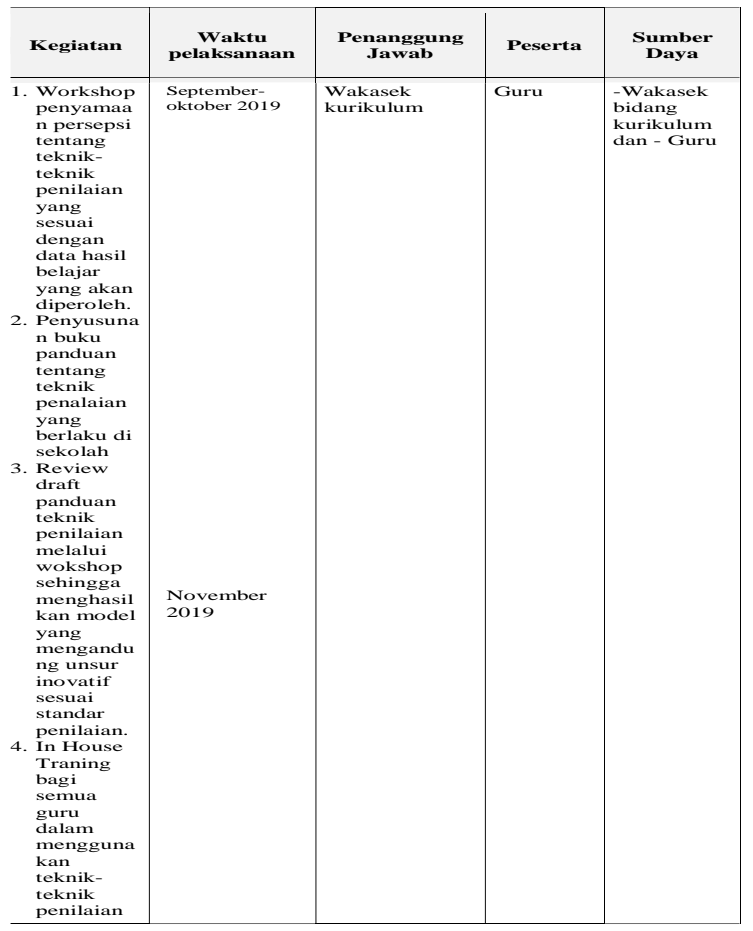

(Sumber: LK3 TPMPS SMA Negeri 6

Mataram Tahun 2019)

\section{e. Standar Pendidik dan Tenaga Kependidikan \\ SMA Negeri 6 Mataram}

Berdasarkan analisis mutu pada standar Pendidik dan tenaga kependidikan diperoleh kelemahan pada tiga indikator yang memerlukan tindaklanjut untuk mengatasi kelemahan pada indikator. Tersebut. Dalam hal ini pemenuhan pada Pelaksanaan program pemenuhan mutu pada standar pendidik dan tenaga kependidikan disajikan pada Tabel 5.

Tabel 5. Pelaksanaan Pemenuhan Mutu Pada standar pendidik dan tenaga kependidikan

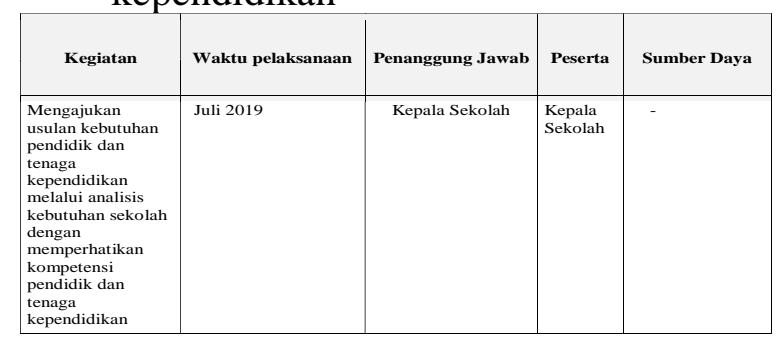

(Sumber: LK3 TPMPS SMA Negeri 6

Mataram Tahun 2019)

\section{f. Standar Sarana dan Prasarana}

\section{SMA Negeri 6 Mataram}

Berdasarkan analisis mutu pada standar sarana dan prasaran pendidikan diperoleh kelemahan pada dua indikator yang memerlukan tindaklanjut untuk mengatasi kelemahan pada indikator. Tersebut. Dalam hal ini pemenuhan pada pelaksanaan program pemenuhan mutu pada standar sarana dan prasarana pendidikan disajikan pada Tabel 6.

Tabel 6. Pelaksanaan Pemenuhan Mutu Pada standar sarana dan prasarana Pendidikan

\begin{tabular}{|c|c|c|c|c|}
\hline Kegiatan & $\begin{array}{c}\text { Waktu } \\
\text { pelaksanaan }\end{array}$ & $\begin{array}{c}\text { Penanggung } \\
\text { Jawab }\end{array}$ & Peserta & Sumber Daya \\
\hline $\begin{array}{l}\text { 1. Kepala sekolah } \\
\text { dan warga } \\
\text { sekolah } \\
\text { menganalisis } \\
\text { kebutuhan } \\
\text { Ruang Kelas } \\
\text { Baru } \\
\text { 2. Kepala sekolah } \\
\text { mengusulkan } \\
\text { pengadaan } \\
\text { Ruang Kelas } \\
\text { Baru } \\
\text { 3. Mengevaluasi } \\
\text { keterlaksanaan } \\
\text { program } \\
\text { pemenuhan } \\
\text { Ruang Kelas } \\
\text { Baru }\end{array}$ & $\begin{array}{c}\text { Tahun anggaran } \\
2019\end{array}$ & Kepala Sekolah & & $\begin{array}{l}\text { Kepala } \\
\text { sekolah, } \\
\text { komite } \\
\text { sekolah }\end{array}$ \\
\hline $\begin{array}{l}\text { 1. Kepala sekolah } \\
\text { dan warga } \\
\text { sekolah } \\
\text { menganalisis } \\
\text { kebutuhan } \\
\text { Ruang Lab. } \\
\text { Bahasa beserta } \\
\text { kelengkapanny } \\
\text { a } \\
\text { 2. Kepala sekolah } \\
\text { mengusulkan } \\
\text { pengadaan } \\
\text { Ruang Lab } \\
\text { Bahasa beserta } \\
\text { kelengkapanny } \\
\text { a } \\
\text { 3. Mengevaluasi } \\
\text { keterlaksanaan } \\
\text { program } \\
\text { pemenuhan } \\
\text { Ruang Lab } \\
\text { Bahasa beserta } \\
\text { kelengkapanny } \\
\text { a }\end{array}$ & $\begin{array}{l}\text { Tahun anggaran } \\
2019\end{array}$ & Kepala Sekolah & & $\begin{array}{l}\text { Kepala } \\
\text { sekolah, } \\
\text { komite } \\
\text { sekolah }\end{array}$ \\
\hline $\begin{array}{l}\text { 1. Kepala sekolah } \\
\text { dan warga } \\
\text { sekolah } \\
\text { menganalisis } \\
\text { kebutuhan } \\
\text { jamban siswa }\end{array}$ & $\begin{array}{l}\text { Tahun anggaran } \\
2019\end{array}$ & & & $\begin{array}{l}\text { Kepala } \\
\text { sekolah, } \\
\text { komite } \\
\text { sekolah }\end{array}$ \\
\hline
\end{tabular}

(Sumber: LK3 TPMPS SMA Negeri 6 Mataram Tahun 2019)

\section{g. Standar Pengelolaan \\ SMA Negeri 6 Mataram}

Berdasarkan analisis pemetaan mutu pada standar pengelolaan pendidikan diperoleh kekuatan pada tiap indikator ketiga indikator. Direkomendasikan untuk mempertahankan meningkatkan pemenuhan tiap indikator. Dalam hal ini pemenuhan pada Pelaksanan program pemenuhan mutu pada standar pengelolaan pendidikan disajikan pada Tabel 7. 
Tabel 7. Pelaksanaan Pemenuhan Mutu Pada standar pengelolaan Pendidikan

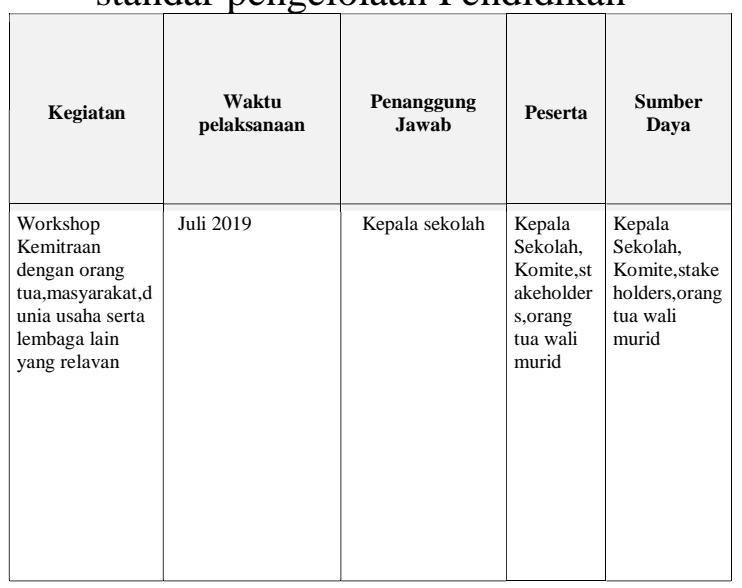

(Sumber: LK3 TPMPS SMA Negeri 6

Mataram Tahun 2019)

\section{h. Standar Pembiayaan}

\section{SMA Negeri 6 Mataram}

Berdasarkan analisis pemetaan mutu pada standar Pembiayaan diperoleh kekuatan pada tiap indikator ketiga indikator. direkomendasikan untuk mempertahankan meningkatkan pemenuhan tiap indikator. Dalam hal ini pemenuhan pada pelaksanaan program pemenuhan mutu pada standar Pembiayaan disajikan pada Tabel 8.

Tabel 8. Pelaksanaan Pemenuhan Mutu Pada standar Pembiayaan

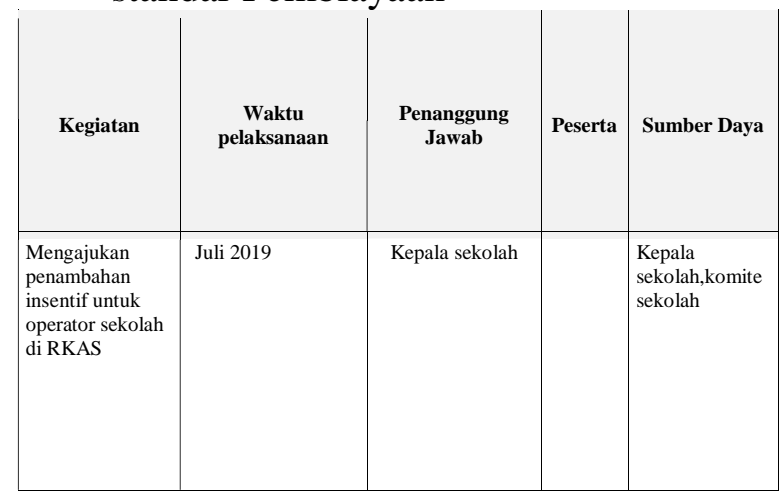

(Sumber: LK3 TPMPS SMA Negeri 6 Mataram Tahun 2019)

\section{PEMBAHASAN}

SMA Negeri 6 Mataram melaksanakan perbaikan mutu pendidikan berdasarkan 5 program dan 5 kegiatan yang telah dirancang dan tertuang dalam Rencana kerja tahunan dan rencana kerja dan anggaran sekolah Program dan kegiatan yang disusun satuan pendidikan secara ideal bertujuan untuk memberikan layanan bermutu kepada para pemangku kepentingan dengan target memenuhi atau melampaui SNP dengan jadwal dan tahapan yang jelas (kemdikbud; 2017: 72-73) adapun 5 program dalam pelaksanaan menjadi 5 kegiatan yang telah dilaksanakan yaitu pada standar pendidik dan tenaga kependidikan yaitu melaksanakan pengajuan ususlan kebutuhan tenaga administrasi, tenaga laboran dan tenaga pustakawan, kemudian pada standar sarana dan prasarana melaksanakan pengajuan usulan dari hasil analisis kebutuhan untuk penambahan ruang kelas baru, penambahan ruang laboratorium terstandar dan pemabahan jumlah jamban siswa.

SMA Negeri 6 Mataram dalam melaksanakan pemenuhan mutu, dari hasil wawancara peneliti dengan kepala sekolah, wakil kepala sekolah dan ketua Tim TPMPS diperoleh keterangan bahwa semua komponen sekolah terlibat aktif dalam kegiatan sekolah, baik dalam menganalisis kegiatan dan racangan program serta memiliki omitmen yang tinggi untuk pemenuhan komponen pemenuhan mutu, hal ini dapat dilihat dari keterlibatan dalam mengikuti kegiatan dan program yang telah diencanakan oleh sekolah.

\section{KESIMPULAN}

Pelaksanaan penmenuhan mutu dilaksanakan oleh semua komponen sekolah, yang berdasarkan rencana pemenuhan mutu yaitu untuk SMA Negeri 6 Mataram 5 Kegiatan yang dilaksanakan tahun 2020. SMA Negeri 6 Mataram dalam melaksanakan pemenuhan mutu, dari hasil wawancara peneliti dengan kepala sekolah, wakil kepala sekolah dan ketua Tim TPMPS diperoleh keterangan bahwa semua komponen sekolah terlibat aktif dalam kegiatan sekolah, baik dalam menganalisis kegiatan dan racangan program serta memiliki omitmen yang tinggi untuk pemenuhan komponen pemenuhan mutu, hal ini dapat dilihat dari keterlibatan dalam mengikuti kegiatan dan program yang telah diencanakan oleh sekolah. 


\section{DAFTAR PUSTAKA}

Anggito, A., \& Setiawan, J. (2018). Metodologi penelitian kualitatif. CV Jejak (Jejak Publisher).

Arikunto, S. (2019). Prosedur penelitian suatu pendekatan praktik.

Aspranawa, A. A. D. P., \& Pravitasari, D. D. (2017, August). System Management of Internal Quality Assurance for College at the University of Islam Balitar Blitar Indonesia. In 2nd International Conference on Educational Management and Administration (CoEMA 2017) (pp. 209-214). Atlantis Press.

Badan Akreditasi Nasional :2019, Pedoman Akreditasi Sekolah Madrasah 2019

Badan Akreditasi Nasional Sekolah Madrasah :2017, Badan Akreditasi Sekolah/ Madrasah Provinsi Nnusa Tenggara Barat.

Hakim, M., \& Fahruddin, F. (2020, May). How to Improve Principal Leadership Effectivity. In 4th Asian Education Symposium (AES 2019) (pp. 325-327). Atlantis Press.

Mursidi, A., Murdani, E., Ting, I. H., \& Wu, J. C. (2019, January). Development of internal quality assurance model in higher education institution. In Proceedings of the 10th International Conference on $E$ Education, E-Business, EManagement and E-Learning (pp. 264-269).

Mursidi, A., Raharjo, T., Sugiyo, S., \& Yulianto, A. (2020). Factual Model of Internal Quality Assurance System of Private Higher Education Institutions in Indonesia. Journal of Education, Teaching and Learning, 5(1), 46-52.

Sumarto, S. (2018). Peran Dan Kredibilitas Badan Akreditasi Nasional Sekolah/Madrasah (Ban S/M) Mewujudkan Sekolah Efektif Melalui Manajemen Mutu. Jurnal Literasiologi, 1(1), 12-12.
Taurina, Z. (2015). Students' motivation and learning outcomes: Significant factors in internal study quality assurance system. International Journal for Cross-Disciplinary Subjects in Education (IJCDSE), 5(4), 2625-2630.

Tavares, O., Sin, C., Videira, P., \& Amaral, A. (2017). Academics' perceptions of the impact of internal quality assurance on teaching and learning. Assessment \& Evaluation in Higher Education, 42(8), 1293-1305. 